Acta Theriologica, Suppl. 4: 41-48, 1997.

PL ISSN 0001-7051

\title{
Developmental stability and population dynamics of shrews Sorex in central Siberia
}

\author{
Vladimir M. ZAKHAROV, Dmitry V. DEMIN, Alexander S. BARANOV, \\ Vyacheslav I. BORISOV, Alexey V. VALETSKY and Boris I. SHEFTEL
}

Zakharov V. M., Demin D. V., Baranov A. S., Borisov V. I., Valetsky A. V. and Sheftel B. I. 1997. Developmental stability and population dynamics of shrews Sorex in central Siberia. [In: Developmental homeostasis in natural populations of mammals: phenetic approach. V. M. Zakharov and A. V. Yablokov, eds]. Acta Theriologica, Suppl. 4: 41-48.

We examined temporal variation in developmental stability measured by fluctuating asymmetry of 10 skull characters in sympatric populations of three shrew species: Sorex araneus Linnaeus, 1758, S. caecutiens Laxmann, 1788 and $S$. tundrensis Merriam, 1900 from one locality in central Siberia with a high four-year-cycle of small mammals. Simultaneous significant changes in developmental stability have been revealed during a population cycle 1986-1989 for all three, most abundant shrew species in the locality. The highest asymmetry for all these species occurred in the year of maximal density. Similar high asymmetry was found for the separate samples of two other species: $S$. roboratus Hollister, 1913 and $S$. isodon Turov, 1924, collected in a peak year 1989 only. The maximal density in 1989 corresponded to the lowest level of breeding success and developmental stability and, vice versa, minimal density in 1986 was accompanied by the highest level of breeding success and developmental stability. These data suggest that overpopulation caused by high density of various small mammals adversely affects an organism's condition. Thus, developmental stability may be used to monitor possible changes in a population even in cases where direct estimation of fitness is difficult.

N. K. Koltzov Institute of Developmental Biology Russian Academy of Science, Vavilov Str. 26, Moscow 117808, Russia (VMZ, DVD, ASB, VIB, AVV); Institute of Evolutionary and Ecological Problems Russian Academy of Science, Leninsky prospect, 33, Moscow, 117071 Russia (BIS)

Key words: Sorex, non-metric traits, fluctuating asymmetry, developmental stability, population dynamics

\section{Introduction}

Population dynamics is still one of the basic problems in the population ecology of mammals (Krebs and Myers 1974, Krebs and Wingate 1985, Sadykov and Benenson 1992, Gurnell 1995). The crucial questions are: (1) How does an organism's condition change with population dynamics? (2) Are these changes in an organism's condition correlated with density? (3) How do biotic and abiotic factors influence population dynamics? (4) Does density limit population growth? 
Developmental stability study may provide an answer, as it provides an integrate information on various factors adversely affecting an organism's condition in natural populations (Zakharov et al. 1991). Developmental stability analysis of two populations of shrews having different types of dynamics has shown that in a cyclic population in central Siberia, developmental stability is negatively correlated with density. In a noncyclic population in southern Finland, there is indication for a positive correlation between these parameters (Zakharov et al. 1991). All these data suggest the autoregulation cyclicity for the first population, where high density is the main factor adversely affecting an organism's condition, leading to a population decline. In the second population, higher density corresponds to better condition of animals and environmental factors prove to be the main limitation for the population growth.

The tasks of this study are: (1) to verify the hypothesis whether the tendency for the negative relation between developmental stability and density and positive relation between breeding success and developmental stability are universal for the cyclic populations, and (2) to check if these negative relationships are valid for the cyclic populations of other sympatric species of shrews.

\section{Material and methods}

We studied shrews from central Siberia (the eastern bank of the river Yenisei, near the Northern Ecological Station of the Institute of Evolutionary and Ecological Problems, Russian Academy of Sciences; $62^{\circ} \mathrm{N}, 89^{\circ} \mathrm{E}$ ). Regular four year cyclicity has been established for small mammals of this locality (Sheftel 1983, 1989). The study period 1986-1989 corresponds to one cycle starting from the year of minimal density 1986 and finishing by the year of high density 1989 . Sympatric populations of eight shrew species occur at this locality. We studied a cycle, 1986-1989, that was unusual in that the regular population increase, which commonly takes place in the third year of a cycle, was interrupted in 1988 by a density decline for all species (Fig. 1).

Annual samples for the whole study period include three most common shrew species: Sorex araneus Linnaeus, 1758, S. caecutiens Laxmann, 1788 and S. tundrensis Merriam, 1900. Only

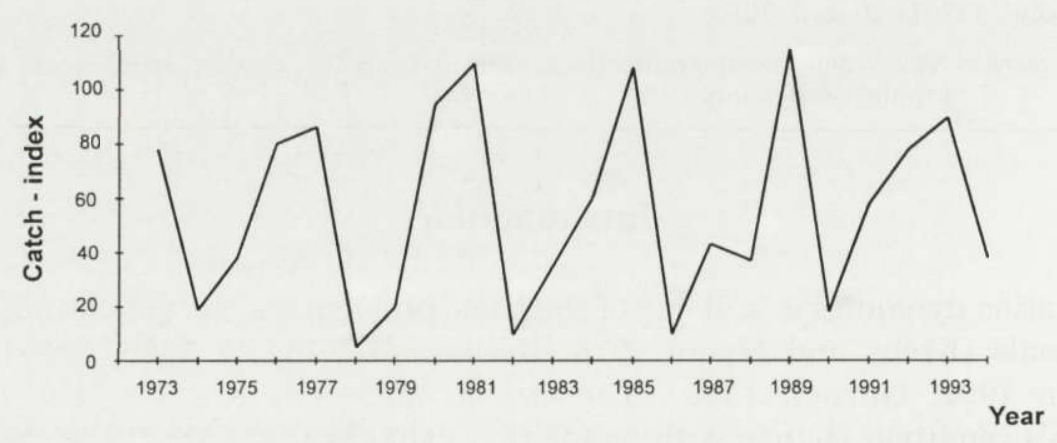

Fig. 1. Population dynamics of 8 shrew species in central Siberia. Catch index - a number of specimens caught by 100 traps per night. 
separate samples for the year of high density (1989) for two other species: S. roboratus Hollister, 1913 and $S$. isodon Turov, 1924 were available for the analysis. The annual trapping period was July-August. See Sheftel (1989) for the description of the trapping techniques.

Catch index was used as a density estimate that was calculated as a number of specimens caught by 100 traps per night. The ratio between the number of immature shrews and the number of breeding adult specimens caught during the summer was used as a breeding success index.

Developmental stability was estimated by fluctuating asymmetry of ten skull characters (Fig. 2). All characters and their asymmetries were uncorrelated with each other. In this study as well as in the previous one (Zakharov et al. 1991) we found no significant directional asymmetry or antisymmetry (definitions in Van Valen 1962, Soulé 1967, Palmer and Strobeck 1986). Mean number of asymmetrical characters per individual was used as an integrated measure of developmental stability (Leary et al. 1983, Zakharov 1987, 1989). Young immature shrews were analysed. Samples of males and females for each year were pooled as no sex differences were found in the parameters studied. We used $t$-test for intersample comparison (Sokal and Rohlf 1991).

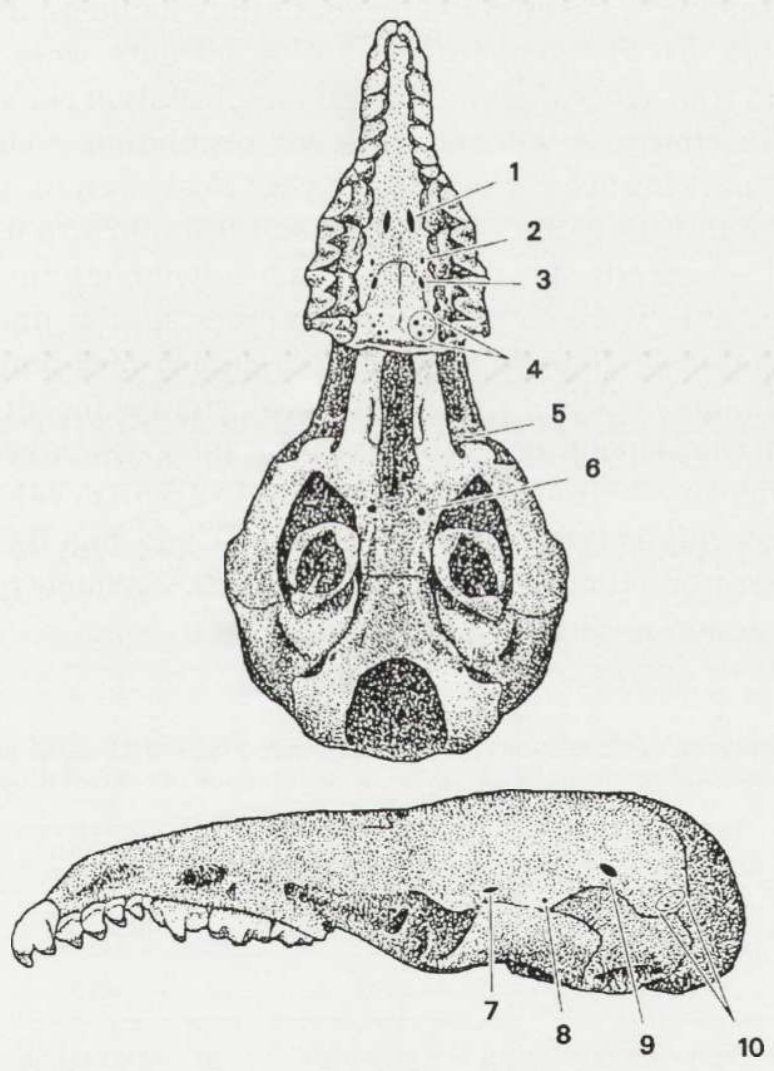

Fig. 2. Cranial characters, as a number of foramina (1-10) examined in the common shrew Sorex araneus: 1 - foramen palatinum anterior, 2 - foramen palatinum posterior accessorius minor, 3 foramen palatinum posterior, 4 - foramen palatinum laminae, 5 - foramen accessorius canalis pterigoideum, 6 - foramen basisphenoidalis lateralis, 7 - foramen parietale anterior, 8 - foramen parietale media, 9 -foramen parietale posterior, 10 - foramen parietale corner. 


\section{Results}

The integrated developmental stability measure (mean number of asymmetrical characters) showed significant changes $(p<0.001, t$-test) during a population cycle in the most abundant shrew species in the locality, the common shrew Sorex araneus. Asymmetry increased from the year of minimal density to the year of maximal density (Table 1 and Fig. 3). Similar significant increases in asymmetry $(p<0.01)$ with the density increase were seen for two other shrew species: Sorex caecutiens and $S$. tundrensis (Table 1 and Fig. 3). As only four years of data were available for analysis, it was not possible to assess the correlation between asymmetry and density, but a tendency for the parallel changes of the parameters was visible for all these species.

For Sorex araneus some data have been obtained earlier (Zakharov et al. 1991). Developmental stability was estimated in that study by fluctuating asymmetry of 13 skull characters. To get comparable results, all data were recalculated and presented as mean frequency of asymmetrical manifestation per character. Despite some difference in character set and different population cycles studied, mean asymmetry index per character proved to be very close even in absolute values (it changed from 0.22 to 0.44 in 1977-1982 yrs and from 0.26 to 0.41 in 1986-1989 yrs) and showed, generally speaking, the same dynamics in both time series compared. Similar data were obtained for two other species under study: $S$. caecutiens and $S$. tundrensis. In spite of some interspecies variation, asymmetry was the lowest in 1986, and reached its highest level, similar for all species, in 1989, ie at the peak of the population cycle. Even in 1988, when strict cyclicity was interrupted by a density decline, we revealed the change in developmental stability coincided with breeding success alteration (Table 1 and Fig. 3). For S. roboratus and $S$. isodon, represented only in samples for 1989, asymmetry values are very close to those for other species in this year.

Table 1. Integrated measure of developmental stability (NA $\pm \mathrm{SE}$ ) of 10 skull characters (see Fig. 2) in 5 shrew Sorex species, collected from the sympatric populations in central Siberia in different years.

\begin{tabular}{|c|c|c|c|c|c|c|c|c|}
\hline \multirow{3}{*}{ Species } & \multicolumn{8}{|c|}{ Years } \\
\hline & \multicolumn{2}{|r|}{1986} & \multicolumn{2}{|r|}{1987} & \multicolumn{2}{|r|}{1988} & \multicolumn{2}{|r|}{1989} \\
\hline & $n$ & NA & $n$ & NA & $n$ & NA & $n$ & NA \\
\hline S. araneus & 20 & $2.60 \pm 0.26$ & 20 & $2.90 \pm 0.28$ & 20 & $3.80 \pm 0.35$ & 20 & $4.10 \pm 0.25$ \\
\hline S. caecutiens & 20 & $2.70 \pm 0.25$ & 20 & $2.55 \pm 0.24$ & 20 & $2.90 \pm 0.26$ & 20 & $4.00 \pm 0.35$ \\
\hline S. tundrensis & 20 & $2.05 \pm 0.37$ & 20 & $3.00 \pm 0.31$ & 20 & $3.60 \pm 0.25$ & 20 & $4.00 \pm 0.27$ \\
\hline S. roboratus & - & - & - & - & - & - & 17 & $4.00 \pm 0.32$ \\
\hline S. isodon & - & - & - & - & - & - & 20 & $3.57 \pm 0.21$ \\
\hline
\end{tabular}


Thus, asymmetry, which is an index of developmental stability, revealed the same regular changes during different population cycles in one species and during the same population cycle for different species of shrews.

Fig. 3. Population dynamics (catch index - a number of specimens caught by 100 traps per night) and breeding success index in sympatric populations of 5 shrew Sorex species in
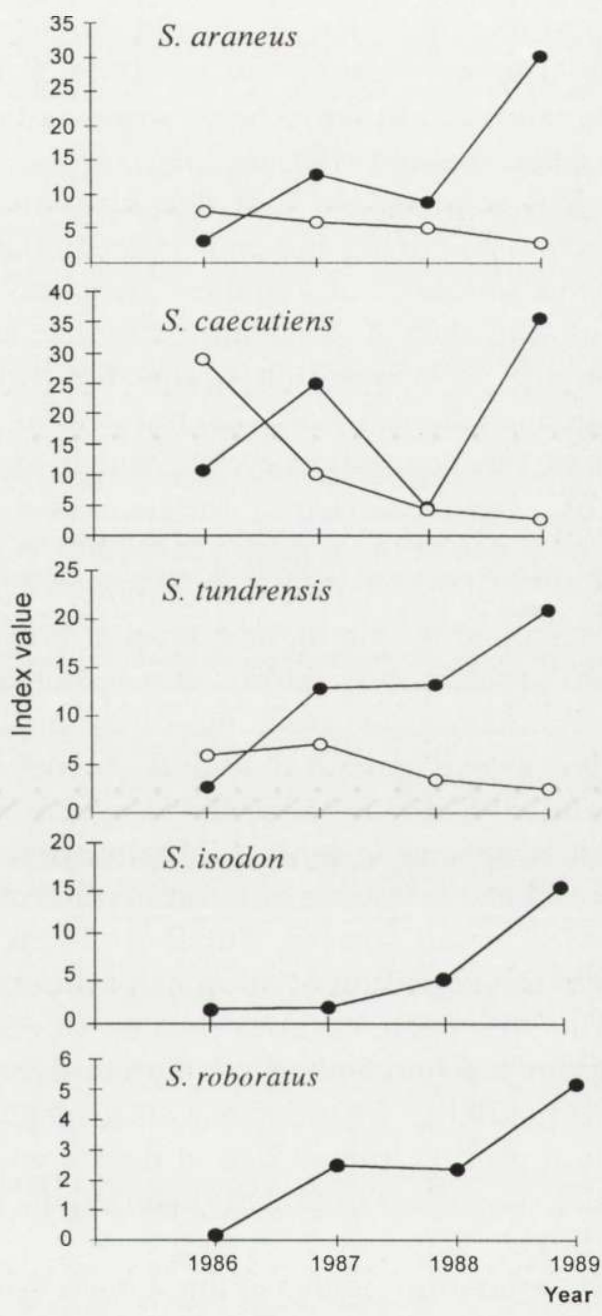
central Siberia in $1986-1989$

$\rightarrow$ Catch index

$-\infty$ Breeding success index

\section{Discussion}

Population growth can be limited by external environmental conditions or by overpopulation, through autoregulatory mechanisms (Koshkina and Korotkov 1975, Shilov 1977, Christian 1978, Sheftel 1989). Both environment and density 
interact in complex ways, but the prevalent effect of each can be distinguished by the simultaneous study of density and organism's condition. In the case of environment dependent regulation, high density would correspond to better environmental conditions and organism status. In the case of density dependent regulation, high density would correspond to the worse organism status and population decrease. Previous study of developmental stability as an index of an organism's condition in Sorex araneus has already illustrated both of these cases described (Zakharov et al. 1991).

This study show that decreases in developmental stability with increasing density seen during one cycle in a population of a common shrew in central Siberia are not unique, but regular. They can be seen for this population in another population cycle 3 years after the first study period. Similar changes can also be seen during population cycles for different species. The latter support the prediction (Sheftel 1989, Zakharov et al. 1991) that social stress during the peak year of the population cycles, which are synchronous for various species at the locality, can be caused by the increased density of different small mammals. The maximal density in a peak year, 1989, corresponded to the lowest level of breeding success and developmental stability. Conversely, minimal density in 1986 was accompanied by the highest level of breeding success and developmental stability for all species under study. In establishing the adverse effect of high density on an organism's condition for different species, we illustrate the importance of studying developmental stability, which can reveal the mechanism of population dynamics. Without these data, synchronous population dynamics for all small mammal species in central Siberia can be interpreted as a result of environmental fluctuations: favorable environmental conditions could correspond to a population increase for all species. But there is an opposite effect - high density adversely affects the condition of animals of different species.

This approach assumes that we can use developmental stability to distinguish different mechanisms of population dynamics. A negative correlation of developmental stability with density corresponds to an adverse effect of overpopulation, while a positive correlation of developmental stability with density indicates the crucial role of environmental conditions in population dynamics (see Zakharov et al. 1991).

Experimental evidence for a decrease of developmental stability under social stress has been established in laboratory rats (Valetsky et al. 1997). The importance of changes in organism's condition, as detected by a decrease in developmental stability, was established by the simultaneous study of various measures of developmental homeostasis: morphogenetic instability under social stress impact in rats accompanied by changes in immune status (Pronin et al. 1997), and overpopulation in vole populations adversely affected cytogenetic homeostasis (Dmitriev et al. 1997). In the previous study of shrew population dynamics, positive correlation of developmental stability with breeding success 
indicates that breeding success is affected by physiological condition of breeding females (Zakharov et al. 1991)

In this study we analyzed an unusual cycle, 1986-1989, where the regular population increase, that commonly takes place in the third year of a cycle, was interrupted in 1988 by a density decline for all species (Fig. 1). This decline was probably caused by weather conditions. In spite of this exceptional situation in 1988, when strict cyclicity was interrupted by a density decline, there was still a positive relation of developmental stability with breeding success for all species. This relation suggests that developmental stability is indeed an important population parameter.

There are some advantages to applying developmental stability measures instead of commonly used fitness estimates, such as breeding success index. For example, developmental stability is more sensitive, as it is possible to reveal adverse changes in organisms before serious changes in demographic patterns appear. Second, it is easily applied, as needed information can be obtained through the analysis of one sample of specimens from the population under study. Even museum collection is sufficient for this porpoise, instead of the whole breeding season study needed for the correct estimation of breeding success. Finally, more adequate information on the condition of pregnant females and their progeny is available through developmental stability study, as breeding success estimates could reflect not only changes in an organism condition, but also predators or climate pressure, etc.

Thus, developmental stability could be recommended as an approach useful for a wide application to monitor possible changes in a population's condition for various species and to distinguish among mechanisms of their population dynamics.

Acknowledgements: We are very grateful to $\mathrm{Dr}$ J. H. Graham and two anonymous referees provided very helpful comments and corrections of English.

\section{References}

Christian J. J. 1978. Neurobehavioural endocrine regulation of small mammal populations. [In: Populations of small mammals under natural conditions. D. P. Snyder, ed]. Pymatuning Laboratory of Ecology, Special Publication 5: 143-158.

Dmitriev S. G., Zakharov V. M. and Sheftel B. I. 1997. Cytogenetic homeostasis and population density in red-backed voles Clethrionomys glareolus and C. rutilus in central Siberia. [In: Developmental homeostasis in natural populations of mammals: phenetic approach. V. M. Zakharov and A. V. Yablokov, eds]. Acta Theriologica, Suppl. 4: 49-55.

Gurnell J. (ed) 1995. Abstracts of the Second European Congress of Mammalogy. Southampton, England: $1-219$.

Koshkina T. V. and Korotkov Yu. S. 1975. [Regulatory adaptations in the population of ruddy vole in the optimum of species range]. Fauna i Ekologiya Gryzunov 12: 5-62. [In Russian]

Krebs C. J. and Myers J. H. 1974. Population cycles in small mammals. Advantages in Ecology Research 8: 267-399. 
Krebs C. J. and Wingate I. 1985. Population fluctuations in the small mammals of the Kluane Region, Yukon Territory. Canadian Field-Naturalist 99: 51-61.

Leary R. F., Allendorf F. W. and Knudsen K. L. 1983. Developmental stability and enzyme heterozygosity in rainbow trout. Nature 301: 71-72.

Palmer R. A. and Strobeck C. 1986. Fluctuating asymmetry: measurement, analysis, patterns. Annual Review in Ecology and Systematic 17: 391-421.

Pronin A. V., Nikolaeva T. N., Deyeva A. V., Zaytseva L. G., Vasil'eva E. I., Kirillicheva G. B., Baturina I. G., Solov'eva M. S. and Zakharov V. M. 1997. Social stress in laboratory rats Rattus norvegicus results in decreased immune competence of the offspring. [In: Developmental homeostasis in natural populations of mammals: phenetic approach. V. M. Zakharov and A. V. Yablokov, eds]. Acta Theriologica, Suppl. 4: 33-40.

Sadykov O. F. and Benenson I. E. 1992. [Population dynamics of small mammals: Concepts, hypotheses, models.] Nauka, Moskva: 1-191. [In Russian]

Sheftel B. I. 1983. [Zonality of populations of shrews in Yenisei taiga.] [In: Animals and natural zonality of Yenisei taiga and forest tundra. E. E. Siroechkovsky, ed]. Nauka, Moskva: 184-203. [In Russian]

Sheftel B. I. 1989. Long-term and seasonal dynamics of shrews in Central Siberia. Annales Zoologici Fennici. 26: 357-370.

Shilov I. A. 1977. [Ecological and physiological backgrounds of population relations in animals.] Moscow University Press, Moskva: 1-261. [In Russian]

Soulé M. E. 1967. Phenetics of natural populations. II. Asymmetry and evolution in a lizard. American Naturalist 101: 141-160.

Valetsky A. V., Dmitrieva I. L., Krushinskaya N. L. and Zakharov V. M. 1997. Social stress impact on developmental stability of laboratory rat Rattus norvegicus. [In: Developmental homeostasis in natural populations of mammals: phenetic approach. V. M. Zakharov and A. V. Yablokov, eds]. Acta Theriologica, Suppl. 4: 27-32.

Van Valen L. 1962. A study of fluctuating asymmetry. Evolution 16: 125-142.

Zakharov V. M. 1987. [Animal asymmetry: population-phenogenetic approach.] Nauka, Moskva: 1-216. [In Russian]

Zakharov V. M. 1989. Future prospects for population phenogenetics. Soviet Science Reviews, Section F 4 (3): 1-79,

Zakharov V. M., Pankakoski E., Sheftel B. I., Peltonen A. and Hanski I. 1991. Developmental stability and population dynamics in common shrew, Sorex araneus. American Naturalist 138: 797-810.

Received 11 October 1995, revised 10 October 1996, accepted 12 June 1997. 